\title{
A DETERMINAÇÃO TRIDIMENSIONAL DA FORMA NAS VILAS DE A. PALLADIO
}

Joubert J. Lancha

Departamento de Arquitetura e Urbanismo

Universidade de São Paulo

Do grande número de vilas projetadas por Palladio entre os anos de 1537 e 1570, um elenco composto por vinte e três delas foi apresentado no Livro II de seu tratado "I Quattro Libri dell'Architettura", publicado pela primeira vez em Veneza no ano de 1570. Revisitando esse elenco e observando o constante alinhavar de relações entre uma e outra vila, é possível identificar os elementos comuns, suas características e variações e desses vínculos extrair seus procedimentos.

A maturação desse processo, construído no estreito intervalo entre obras, será destacada com a observação das recorrências, das passagens, dos desvios das correspondências e dos abandonos e aperfeiçoamentos sofridos por determinados elementos ao longo desses anos, delineando assim, entre esses edifícios, um "texto projetivo"; elaborado na prática e re-escrito por Palladio em seu tratado. Para essa leitura nos apoiamos nessa que é sua obra teórica de maior importância, imaginando que uma chave interpretativa dessa arquitetura reside justamente em estabelecer um patamar de diálogo entre os problemas advindos do projeto e aqueles expressos no âmbito de seu texto escrito.

Procuramos discutir o procedimento de determinação da forma, comparando os projetos de vila e focalizando aqui o projeto para a inteira propriedade agrícola e não só a casa dominical, a "casa de vila" como era descrita por Palladio. Essa opção tem como ponto de referência o estudo "Geometria palladiana: le ville" desenvolvido por Rudolf Wittkower e publicado em 1949 no livro Principî architettonici nell'età dell'Umanesimo. Nesse ensaio Wittkower demonstra que com a análise das casas de vila é possível averiguar a interpretação palladiana das "regras universais" e desse estudo resulta o celebre esquema geométrico das plantas das vilas.

Desde o inicio imaginamos que uma observação restrita a planta, não seria suficiente para dar conta da complexidade estabelecida por Palladio na relação entre as "partes" do edifício e suas proporções. Imaginamos que, um estudo onde a analise tridimensional privilegiasse a totalidade da vila poderia se aproximar mais às questões formais propostas por essa arquitetura. Elaboramos assim essa análise, através da construção 
de um acervo de modelos, realizados em papel e madeira e elaboramos desenhos tridimensionais que desconstruiam cada vila, para posteriormente coloca-los em confronto.

A perspectiva dessa análise com modelos, surge em fidelidade com a idéia de que toda linguagem possui uma estrutura que não é possível criticar com seus próprios termos. De fato, para poder criticar uma linguagem é necessário dispor de uma segunda linguagem que tenha certa relação com ela mas que possua outra estrutura. Por isso o modelo não é mimético, não reproduz in totum todas as filigranas de seu original. Interessa-nos que ele traga à tona a lógica interna do projeto analisado e, ao mesmo tempo lhe seja embutida a capacidade de estar aberto para novas operações.

\section{A vila palladiana}

Desde os primórdios do gênero da literatura sobre a vila sempre houve uma ambigüidade ao determinar se com o termo "villa" se fazia referência à propriedade, aos edifícios situados no interior de uma propriedade ou exclusivamente à residência do proprietário. Na Antigüidade a casa desse último era denominada "villa urbana" para estabelecer uma distinção da "villa rustica" destinada ao alojamento do feitor e dos dependentes, edifícios que faziam parte da mesma propriedade. A referência primeira para as vilas do renascimento é a vila da Roma antiga, o termo vila indica sempre para os romanos um complexo construído situado fora dos muros urbanos, categoria essa bastante aberta e que reúne uma vasta produção.

Assim, como os escritores do renascimento ${ }^{1}$, Palladio utiliza o termo vila para indicar a inteira propriedade fundiária da qual faz parte além dos diversos edifícios pertinentes à produção agrícola, também a habitação do proprietário que ele define como "casa de vila". Com variações, a maioria dos projetos de vila, respondem a uma requisição comum, a um programa mais ou menos similar. A vila era formada basicamente por duas partes distintas: um corpo central, onde funcionava a casa para habitação do proprietário e sua família, e por alas laterais, próprias ao uso e

\footnotetext{
${ }^{1}$ O contato de Palladio com os tratados agronômicos de Columella, Varrone, Catone e (Rutilio) foi estabelecido provavelmente através de Daniele Bárbaro que os cita no capítulo dedicado à vila de sua tradução comentada de Vitruviu. I dieci Libri dell'architettura di M. Vitruviu trado tti e commentati da Mons. Daniel Barbaro eletto Patriarca d'Aquileia..., Venezia 1556, libro VI, cap.IX, p.298.cfr Ackerman;J. La villa.p.121
} 
funcionamento de uma fazenda. No capítulo XIII do segundo livro de seu tratado: "Do arranjo das Casas", Palladio esclarece que "Duas espécies de construçoes são pedidas na vila: uma para a habitação do patrão e de sua familia; a outra para governar e tomar conta das entradas e dos animais da vila. Porém o sitio deverá ser compartilhado de modo que nem aquela a esta, nem esta àquela seja um obstáculo..'”. Esse parágrafo inicial nos indica uma primeira disposição de Palladio na divisão, composição e implantação dos vários espaços requeridos para uma vila. Primeiro a determinação de um número reduzido de elementos, "duas espécies de construções", transformando assim o tradicional complexo da vila em um todo orgânico composto por dois únicos edifícios e entre eles se reduziriam os contrastes, potencializando os vínculos formais de um para o outro corpo construído.

A vila, como proposta por Andrea Palladio, pode ser escandida em duas partes principais: casa de vila e barchess $a^{3}$. E da análise dos projetos é possível verificar que o vínculo entre esses dois elementos é sempre uma questão importante, jamais a barchessa é colada diretamente ao bloco da casa de vila. Palladio usa de um artifício, para estabelecer a conexão entre um e outro bloco, adota um elemento de ligação, que pode ser uma arcada ou galeria (loggia) que como estaremos vendo irá assumir uma grande importância na definição dos espaços e da forma na vila palladiana. Com isso a ligação entre a casa de vila e a barchessa é realizada, sem submeter uma parte à outra. Junto a esses dois elementos inicias de divisão da vila acrescentaríamos, portanto, esse terceiro e dividiríamos o complexo em três partes principais: a primeira é a própria "casa de vila" e seguem a arcada e a barchessa. Do conjunto de vilas colocadas no segundo dos Quatro Livros (vinte e duas) a grande maioria (dezessete) apresenta essas três alas, mesmo que algumas delas estas não tenham sido inteiramente construídas. A arcada, ou terraço funciona como um edifício de transição entre a "casa de vila" e a barchessa - que é um elemento típico da arquitetura veneta e diretamente ligado à produção agrícola, onde funcionam os estábulos e a provisão alimentar - e ainda é responsável pela possibilidade de "passeio ao coberto" 4 na vila. Palladio procura com isso estabelecer entre esses

\footnotetext{
2 Palladio; A. I Q.L. L II cap.XIII

${ }^{3}$ Barchessa é um edifício típico da arquitetura veneta, que serve para guarda de equipamentos agrícolas, animais e reserva de produtos agrícolas.

4 "As coberturas para as coisas de vila serão feitas tendo respeito às entradas e aos animais e de tal modo ligadas à casa do patrão, que para todo lugar se possa andar ao coberto: para que nem as chuvas nem os ardentes Sóis do Verão lhe sejam incômodos ao ir ver seus negócios, isto será também de
} 
edifícios uma relação orgânica revendo a tradição que no decorrer do séc. XV determinou a construção da maior parte das vilas na região do Vêneto. ${ }^{5}$ Articular os diversos edifícios de uma tradicional fazenda, para compor um único na somatória com a casa de vila, é uma grande inovação proposta por Palladio para a arquitetura da vila. Mas também, a composição entre essas partes é resolvida dentro da lógica de simetria, do ideal de beleza tão caro e tão perseguido por Palladio em seus projetos. Ideal que encontra, no desenvolvimento dos projetos para as vilas, seu objeto de reflexão. Esse conjunto de edifícios é resolvido em um todo orgânico; um eixo central organiza os diversos corpos, a "casa de vila" ocupa o centro dessa composição e em suas duas laterais, dois blocos rústicos são simetricamente colocados (arcada e barchessa).

grandíssima utilidade para colocar ao coberto lenha e infinitas outras coisas davila, que seriam estragadas pelas chuvas e pelo Sol; além do que estes pórticos são de muito ornamento.” Palladio; A. LII cap.XIII

5 São dois os tipos de vila no Vêneto no decorrer do séc. XV: o mais comum era aquele constituído pela casa do colono construída modestamente no interior de um pátio formado por algumas estruturas instrumentais, dispostas envolta de uma área central pavimentada. A maior parte desses complexos possuía além da residência do proprietário, que os vênetos chamavam "barchessa", um longo celeiro (granaio) com um lado inteiramente aberto para a praça central coberto por um alpendre construído sobre pilastras, ou arcos que continham sobre o lado fechado, os estábulos para animais, armazéns e os espaços destinados para a habitação dos dependentes. Havia também, quase sempre, um ou mais pombais, elevados em altas torres que em geral tinham a forma quadrada. Esse complexo era fechado por um muro baixo cujo ingresso principal se abria sobre uma das estradas de acesso. Se acaso essas estruturas viessem a ser utilizadas pelas famílias patrícias para férias, às partes residenciais vinha conferida certa elegância, adaptando características decorativas típicas dos palácios venezianos como as cornijas góticas esculpidas que enquadravam janelas e portas. Porém parece provável que os proprietários ali não permaneciam per longo tempo, uma vez que a vida na cidade oferecia muitas oportunidades de divertimento. $\mathrm{O}$ segundo tipo de residência rural era projetado para satisfazer justamente essas exigências e seu protótipo não era a grande fazenda, mas sim, como no caso das vilas toscanas os castelos medievais da região. A vila-castelo, assim como aparece em uma gravura e representa aquele que deveria constituir o exemplo mais significativo, o Barco (propriedade) da Rainha Cornaro em Altivole, próximo a Treviso. Um muro alto com merlões e torres nas quinas, a entrada imponente dos castelos antigos que, concebidos originalmente para resistir aos assédios nesse caso possuíam um valor puramente simbólico. Os aparatos agrícolas e as provisões poderiam ser mantidas no interior da área murada, ao longo da face interna da muralha. A zona residencial era o centro do complexo e razão da sua existência. E por isso era concebida como uma obra de arte As residências que ainda existem devem ter sido concebidas por arquitetos e com efeito, espelham o gosto corrente em Veneza e nas cidades da terraferma, no primeiro Renascimento. O exemplo mais significativo é representado pela via Porto-Colleoni em Thiene ao norte de Vicenza e construída por volta dos anos quarenta do séc. XV. Um elemento formal, típico dos palácios venezianos tardogóticos o conjunto central de janelas que ilumina um salão aberto também na parte de trás do edifício, se combina muito com as arcadas no piso térreo, emoldurado em suas duas laterais pelas torres ligeiramente deslocadas para frente. O perfil da parte superior do edifício é em ameias, totalmente denteado como também sua parte central, atualmente escondida por uma cobertura moderna. 
Como ala responsável pelas atividades que se vinculam a produção agrícola, esses edifícios funcionam como dois braços horizontais que na maior parte das vilas estão organizados na forma de um duplo "L", como podemos ver na vila Pisani Bagnolo. Mas esse conjunto de edifícios pode também ter o desenho de um semi-círculo como na vila Badoer ou de uma longa barra completamente horizontal como nas vilas Emo e Barbaro, ou ainda derivar da somatória de padrões, como explorado quinze anos mais tarde, que nas três vilas anteriores, na vila Trissino a Meledo.
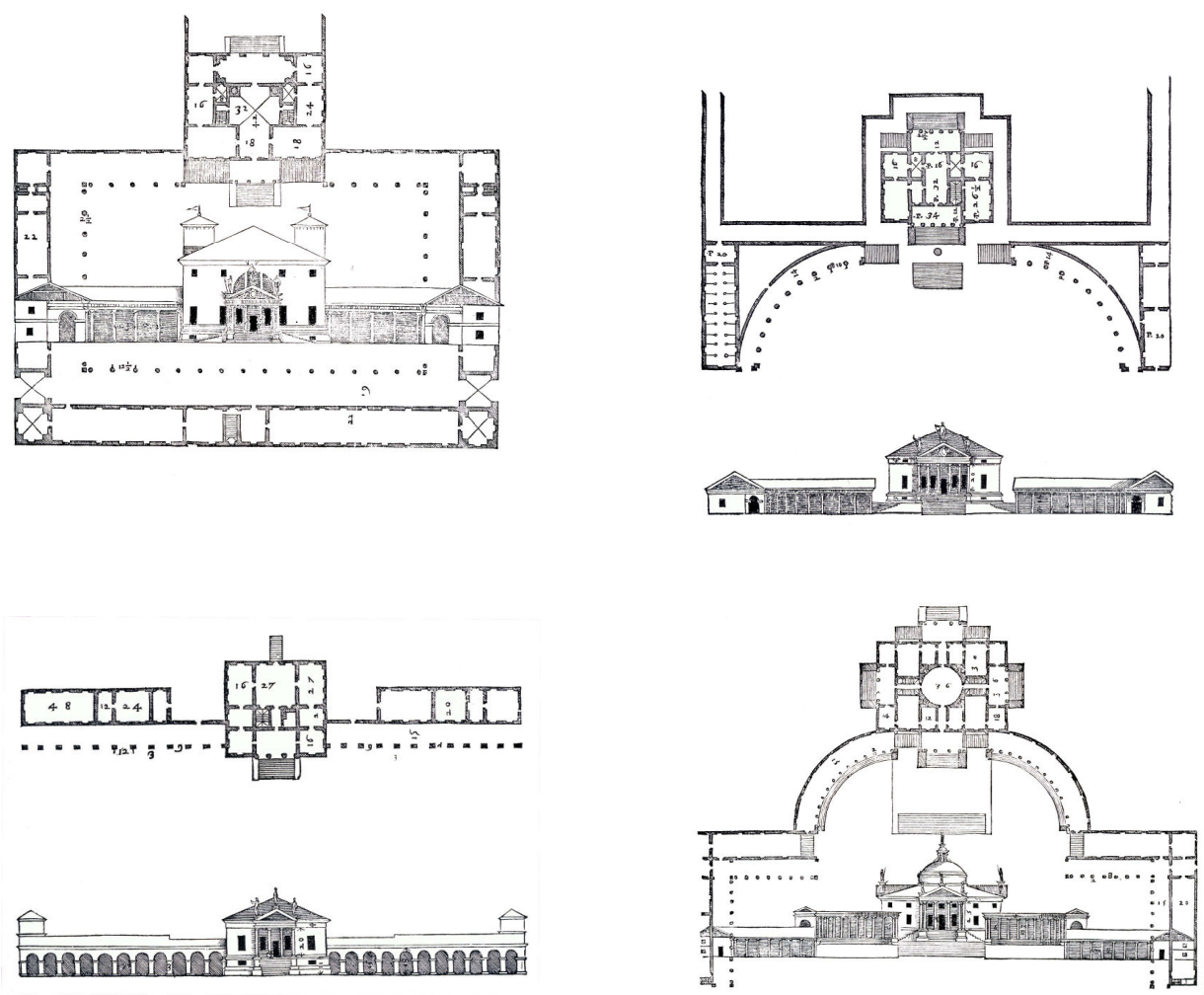

Ilustração 1Planta e elevação do I Quattro Libri: vilas Pisani Bagnolo, Badoer, Emo e Trissino.

FIGURAS: planta e elevação das vilas Pisani Bagnolo; Badoer, Emo e Trissino) 
Esses corpos, barchessa e arcada que nascem nas laterais da casa de vila, configuram um pátio porticado aberto que é utilizado, na maior parte das vilas, para a realização de atividades afeitas à produção agrícola. Pisani em Bagnolo é a primeira vila exposta no tratado, em sua apresentação fica evidente que o pátio é a referencia primeira, revelando a importância desse elemento na organização do conjunto de edifícios. Espaço central de onde pode ser descrito todos os outros elementos ao seu redor, toda a composição, no texto sobre a vila Pisani, depois de anotar a localização da vila e o nome de seu proprietário, Palladio escreve; "De um e de outro lado do pátio estão os estábulos, os porões, os celeiros e outros lugares similares para o uso da vila. As colunas dos pórticos são de ordem Dórica. A parte central desta fábrica é para a habitação do patrão: o piso dos primeiros cômodos é alto do solo sete pés; abaixo estão as cozinhas e outros lugares similares para a familia."

O desenho para esse pátio central é variável, ele pode ser mais ou menos aberto, decorre da forma escolhida para a arcada e do tamanho da barchessa que é função diretamente vinculada à extensão da propriedade e disponibilidade financeira do proprietário. A solução em duplo "L" é a mais freqüente e determina uma planta em forma em "U" para o conjunto da vila, permitindo assim, que a casa de vila no centro dessa composição fique franqueada (frente e fundos) para a paisagem, como ocorre, por exemplo, nas vilas Badoer, Zeno, Sarraceno, Poiana e Godi. Já, na parte posterior da vila Pisani em Bagnolo -1542, como podemos ver na ilustração do tratado, é projetado um pátio completamente fechado em seus quatro lados, diferente da solução dada para a vila Emo -1557, onde dois pátios completamente abertos ficam de frente para as duas barchesse. Estes dois casos podem ser identificados como dois extremos de uma seqüência de variáveis, onde cada vila recebe um desenho particular para a articulação dessas que são suas partes principais. Não existe, portanto nas plantas das vilas expostas no tratado, a repetição de uma mesma solução, o formato do pátio e também o desenho para o encontro da arcada com a casa de vila revela essa riqueza de possibilidades advindas da composição dessas três partes.

A arcada que nasce da casa de vila e se desenvolve em suas duas laterais, prolonga a fachada da vila e termina por constituir um outro eixo na composição desses edifícios; perpendicular ao primeiro, esse reforça o predomínio da relação frente/fundos na implantação da vila. Essa relação evidente na vila Emo, esta presente em todas as vilas exceto é claro naquelas onde, arcada e barchessa não existem ou não foram vinculadas diretamente à casa de vila como nas vilas Cornaro, Malcontenta e Rotonda. 
Observando as elevações frontais das vilas que acompanham as plantas no tratado, fica evidente essa disposição. Mas também podemos perceber que entre essas três partes (casa de vila, arcada e barchessa) é estabelecida uma hierarquia. A altura adotada e o nível escolhido para a implantação de cada uma delas estabelece um jogo onde a casa de vila assume também aqui sua posição de destaque em relação a todo o complexo.

Arcada e barchessa são implantadas ao nível do terreno, já a implantação da casa de vila é variável: muitas vezes ela se assenta alguns metros abaixo dessas, criando um piso semi-enterrado que funciona para acomodar os espaços de serviço da casa, elevar seu piso principal garantindo uma maior salubridade e destacar a casa de vila acima do piso rústico; essas mesmas relações são ainda garantidas quando, em uma outra alternativa de implantação, o piso de serviços nasce ao nível do chão.

Mas essa disposição não é uma norma imutável, como de costume, na obra de Palladio existe um princípio e o novo projeto é a ocasião para tencioná-lo, também na questão específica das hierarquias entre essas três partes são muitas as variações. Podemos novamente escolher duas vilas que funcionam como pontos extremos nesse processo de hierarquização dos espaços, são as vilas Repeta 1557 e Trissino 1570. O projeto para a vila de Mario Repeta é singular no interior da produção de Palladio: uma estrutura em pórtico contínuo de ordem dórica, edificada em um só piso e totalmente desenvolvida entorno a um pátio retangular de dois quadros. Nessa vila, destruída por um incêndio no séc. XVII, não existe uma hierarquização ${ }^{6}$ entre o bloco do proprietário que domina a composição e os anexos agrícolas, ambos estão resolvidos em uma mesma estrutura horizontal. Palladio no texto de apresentação dessa vila evidencia essa relação presente no desenho; "e porque a parte para a habitação do patrão, e aquela para uso de vila são de uma mesma ordem; o quanto aquela perde de grandeza por não ser mais eminente que esta; tanto esta de vila acrescenta ao seu debito ornamento e dignidade fazendo-se igual àquela do patrão com beleza de toda a obra". ${ }^{7}$

6 Vários autores afirmam que o desenho da vila, por não apresentar a normal hierarquização dos blocos, era a expressão do sentimento de igualdade, provável fruto de um preciso estimulo dos clientes para respeitar as idéias heterodoxas e igualitárias da família Repeta (Mario Repeta é descendente de uma antiga família nobre vicentina e convertido à reforma religiosa e denunciado ao Santo Uficio em 1569), inquieta protagonista da vida civil vicentina do Quinhentos. Manfredo Tafuri percorre o perfil dos clientes aproximando-os das escolhas formais que realiza palladio. Committenza e tipologia nelle ville palladiane, Bollettino CISA XI, 1969, p.120-136

7 PALLADIO; A. I Quattro Libri, LII, cap XV. 
A vila Trissino em Meledo é composta por uma casa dominical desenvolvida em planta central, colocada entre duas amplas galerias ${ }^{8}$ (loggie) semi-circulares, que conduzem a um nível mais baixo, onde em forma de "L" duas barchesse/arcada com funções agrícolas, fecham o complexo. Todos esses elementos, aproveitando os desníveis do sítio são hierarquicamente assentados e conformariam um amplo pátio.

Precedentes para esse projeto, da experiência com a vila Badoer de 1554 Palladio recupera as galerias (loggie) e o patamar intermediário entre o pátio e a casa de vila, que em Meledo é potencializado. Mas é também inequívoca a vinculação com a vila Almerico, seja pela adoção da sala central circular com cúpula quanto pelo uso dos quatro pronaus; ainda que só dois deles tenha sido colocado externo ao bloco construído, o que nos faria pensar mais fortemente que esta faz prelúdio à Rotonda9. Palladio encontra em estruturas antigas, referencias para essa implantação e disposição em terraços, como é o caso do templo da Fortuna Primogênita em Palestrina e do templo de Ercole Vincitore em Tivoli, visitados, levantados e desenhados por Palladio, provavelmente durante sua viagem de 1555.

Do grande pátio da vila, através de uma grande escada, aproximadamente vinte e oito metros de largura (80 pés), se acende a um patamar central para posteriormente acessar a casa de vila através da escada do pronau. Com a elevação representada no tratado, é possível verificar que essa implantação, somada a planta centrípeta da casa de vila - que culmina em sua sala circular coberta em cúpula - é bastante cenográfica. Mas esse encontro de elementos revela também um antagonismo; a idéia da casa de vila sem uma fachada prioritária e dessa forma vinculada com o sítio ${ }^{10}$ e a paisagem circundante, parece se contrapor ao grande par de loggie e

8 Loggia é o nome de um elemento arquitetônico difundido na arquitetura italiana, sobretudo aquela do séc.XVII, como galeria ou pórtico, aberto integralmente para almenos um dos lados e sustentado por colunas e arcos. Geralmente uma loggia vem realizada no piso térreo, mas também no primeiro piso, e nesse caso se construída sobre uma outra no piso térreo é chamada de loggia doppia.

9 Expondo o projeto da vila Trissino, Lionello Puppi discute de forma aprofundada a questão da precedência entre as vilas Rotonda e Trissino, mostrando que é um problema ainda aberto e avança a hipótese de que Palladio possa ter retomado o argumento e preparado para os Trissino entre 15581562, em função dos "Quattro Libri”, exasperando os motivos para oferecer um modelo. Puppi Lionello. Andrea Palladio, p.228-230.

${ }^{10}$ PALLADIO; A. I Quattro Libri, LII, cap XV. "O sítio é belíssimo: porque é acima de uma colina, a qual é banhada por um agradável riacho, e está no meio de uma muito espaçosa planície, e ao lado de uma muito freqüente rua. $\mathrm{Na}$ sumidade da colina tem de estar a Sala Redonda, circundada pelos cômodos, e por isso tão alta que receba a luz por cima daqueles." 
patamares que caracterizam o conjunto através de uma ótica perspetivista. Oposição que não se evidencia: na vila Badoer, já que o bloco da casa de vila tem um único eixo de acessos (frente e fundos) permanecendo impenetráveis suas duas fachadas laterais; também na vila Rotonda uma vez que barchessa e arcada descoladas da casa de vila.

Percebemos portanto a importância desses três elementos para a definição tridimensional do complexo da vila para Palladio. Utilizando a arcada como um elemento de forma mais flexível para construir a articulação entre os dois outros blocos (casa de vila e barchessa) e conseguir criar uma gama enorme de alternativas de composição entre essas três partes que compõe a vila para Palladio. 